\title{
Transgenerational regulation of cbln11 gene expression in the olfactory rosette of the European sea bass (Dicentrarchus labrax) exposed to ocean acidification
}

\author{
Mazurais David ${ }^{1,}{ }^{*}$, Servili Arianna ${ }^{1}$, Noel Cyril ${ }^{1}$, Cormier Alexandre ${ }^{2}$, Collet Sophie ${ }^{1}$, \\ 1 IFREMER, Univ Brest, CNRS, IRD, LEMAR, F-29280, Plouzané, France \\ 2 IFREMER, SEBIMER, F-29280, Plouzané, France \\ * Corresponding author : David Mazurais, email address : dmazurai@ifremer.fr
} Leseur Romane ${ }^{1}$, Le Roy Maelenn ${ }^{1}$, Vitré Thomas ${ }^{1}$, Madec Lauriane ${ }^{1}$, Zambonino-Infante Jose-Luis ${ }^{1}$

\begin{abstract}
:
Elevated amounts of atmospheric $\mathrm{CO} 2$ are causing ocean acidification (OA) that may affect marine organisms including fish species. While several studies carried out in fish revealed that OA induces short term dysfunction in sensory systems including regulation of neurons activity in olfactory epithelium, information on the effects of OA on other physiological processes and actors is scarcer. In the present study we focused our attention on a European sea bass (Dicentrarchus labrax) sghC1q gene, a member of the C1q-domain-containing (C1qDC) protein family. In vertebrates, C1qDC family includes actors involved in different physiological processes including immune response and synaptic organization. Our microsynteny analysis revealed that this sghC1q gene is the orthologous gene in European sea bass to zebrafish (Danio rerio) cbln11 gene. We cloned the full length cbln11 mRNA and identified the different domains (the signal peptide, the coiled coil region and the globular C1q domain) of the deduced protein sequence. Investigation of mRNA expression by qPCR and in situ hybridization revealed that cbln11gene is especially expressed in the non-sensory epithelium of the olfactory rosette at larval and adult stages. The expression of cbln11 mRNA was analysed by qPCR in the first generation (F0) of European sea bass broodstock exposed since larval stages to water pH of 8.0 (control) or 7.6 (predicted for year 2100) and in their offspring (F1) maintained in the environmental conditions of their parents. Our results showed that cbln11 mRNA expression level was lower in larvae exposed to OA then up-regulated at adult stage in the olfactory rosette of FO and that this up-regulation is maintained under OA at larval and juvenile stages in F1. Overall, this work provides evidence of a transgenerational inheritance of OA-induced up-regulation of cbln11 gene expression in European sea bass. Further studies will investigate the potential immune function of cbln11 gene and the consequences of these regulations, as well as the possible implications in terms of fitness and adaptation to OA in European sea bass.
\end{abstract}




\section{Highlights}

Cbln11 mRNA is mainly expressed in the olfactory rosettes and in the gills of European sea bass.

Cbln11 mRNA expression is localized in the non-sensory epithelium of the olfactory rosettes. Long term exposure to ocean acidification induces a stimulation of cbln11 mRNA expression in the olfactory rosette of European sea bass. Ocean acidification-induced stimulation of cbln11 mRNA expression suggests a regulation of innate immune function. 


\section{Introduction}

Ocean acidification (OA) due to increasing atmospheric carbon dioxide is a major environmental concern, with the potential to affect the marine ecosystem [1-3]. Several studies have highlighted a range of severe biological effects (growth, calcification, immune defense, etc.), on calcifying organisms such as corals and invertebrates $[4,5]$. Although most fish can efficiently cope with an OAinduced acid-base disturbance thanks to ionic transport through specialized gill ionocytes, resulting physiological tradeoffs may induce numerous effects [6-9]. Among them, impacts on neurosensory systems (olfaction, vision and hearing) were reported with alterations of several behavioural parameters (e.g. predation, orientation) that can affect individuals' fitness [10-15]. Even if these effects have been recently subjected to debates, the behavioural impact of OA is undoubtedly the most documented [16]. Increased calcification of otolith as well as metabolic shift is also sensitive endpoints induced by exposure of fish to OA [17-25]. Additionally but not finally, fewer studies suggest regulation of other physiological processes, such as the complement system (Bresolin de Souza et al., 2016) or the reproductive function [26-28].

Literature reported transcriptomic and proteomic approaches aiming at identifying globally and without a priori the effect of OA on gene expression profile in different fish tissues. Albeit these "omics" approaches have revealed unexplored potential effects on physiological processes, most of them are far to be completely understood [29-33]. Furthermore, the ecological implications of OA on fish species are uncertain since they depend on their potential for acclimation and adaptation to long term exposure to OA within and across generations [34-36]. Depending on phenotypic endpoints considered, some (e.g. behavioural impairment) persist while others (expression of genes) fluctuate within generation as a result of the exposure duration $[11,37,38]$. The potential for transgenerational acclimation depends on the species considered since literature reports several examples where exposure of parents to acidification has conferred or not benefits to their offspring [35, 39, 40]. It must be noted that information related to long term impact of OA exposure on marine fish species exhibiting long life cycle (>3years) is very scarce.

In order to better decipher the short and long term impact of OA on a marine fish species of ecological and economic importance, we exposed European sea bass (Dicentrarchus labrax) from hatching until adult stage (four years old) to water $\mathrm{pH}$ (expressed in total scale) of 8.0 (control, $\mathrm{PCO}_{2} \approx 1520 \mu \mathrm{atm}$ ) or 7.6 (predicted for year $2100, \mathrm{PCO} 2 \approx 590 \mu \mathrm{atm}$ ). Several phenotypical analyses were performed at different life stages revealing limited but significant effects of OA on parameters related to growth, development and digestive enzyme activities [41-43]. Surprisingly, the microarray approach performed at larval stage did not reveal any mRNA expression significantly regulated by OA [43]. Considering that the quantitative PCR (qPCR) approach generally showed greater dynamic range allowing detection of smaller changes in mRNA levels, we decided to investigate by dedicated qPCR approach the expression level of a mRNA corresponding to an Expressed Sequence Tag (EST) which tended to exhibit not statistically significant lower microarray hybridization signal in larvae exposed to pH7.6. This EST represented a cDNA sequence of a member of the C1q-domain-containing (C1qDC) protein family.

The $\mathrm{C} 1 \mathrm{qDC}$ family includes proteins containing a globular $\mathrm{C} 1 \mathrm{q}$ domain and has been found in organisms ranging from bacteria to mammals including teleost $[44,45]$. The C1qDC family can be divided into four sub-families (C1q, C1q-like, cghClq and sghC1q) based on their structural characteristics [44]. While hundreds of C1qDC proteins exist in some invertebrate phyla, several dozen have been found in vertebrate species including zebrafish (Danio rerio) [46, 47]. Depending on their $\mathrm{C} 1 \mathrm{q}$ domains, some $\mathrm{C} 1 \mathrm{qDC}$ proteins (e.g. sghC1q, C1q) have been shown to participate in a 
series of immune responses in different invertebrates and vertebrates species including fish $[45,48$ 52]. While C1qDC proteins are also known to have other roles related to intracellular processes (e.g. cghC1q) and synapse organization (e.g. C1q-like) in different mammalian species, very few information about functions of $\mathrm{Clq}$ sub-family proteins is available in fish [44, 53-55].

In the present study, we reported the full length cDNA cloning and characterization of a novel C1qDC gene (sghC1q) from European sea bass. The determination of its flanking genes in European sea bass genome allowed to provide an orthology assignment with respect with zebrafish by a microsynteny analysis. We investigated expression profile of the transcript throughout larval development and among different tissues in fish reared in normal condition by qPCR, and we analysed its distribution in the olfactory rosette by means of in situ hybridization. We then compared the mRNA expression levels at larval and adult stages in two successive generations (F0 and F1) of European sea bass exposed to a water $\mathrm{pH}$ of 8.0 or 7.6. This work gives new insights related to a member of C1qDC family in a teleost species and contributes to better understanding the impact of $\mathrm{OA}$ in a marine fish species. 
Material and methods

\section{Animal and experimental conditions}

The F0 population of European sea bass in this study was the same as one used in previous works that examined the impact of OA during larval development and at adult stage [38, 43]. Sea bass were maintained from larval to adult stage (four years post-hatching) in two $\mathrm{pH} / \mathrm{PCO} 2$ conditions [i.e., $\mathrm{PCO} 2 \approx 590 \mu$ atm for the control group at $\mathrm{pH}$ total $=8, \mathrm{PCO}_{2} \approx 1520 \mu$ atm for OA condition at $\mathrm{pH}$ total $=7.6]$. The experimental conditions were chosen based on the IPCC Representative Concentration Pathway (RCP) 6.0 and IPCC RCP8.5 scenario predicting a $\triangle \mathrm{PCO} 2$ of $\approx 500 \mu \mathrm{atm}$ and $\approx 1000 \mu \mathrm{atm}$ by the end of the present century, respectively [56]. The rearing conditions of F0 population throughout all life stages are detailed in the previous papers [38, 43]. Briefly, the seawater was pumped from a depth of $20 \mathrm{~m}$ approximately, $500 \mathrm{~m}$ from the coastline in the Bay of Brest, first filtered using a sand filter, heated, degassed using a column. Larvae were maintained at $19^{\circ} \mathrm{C}$ in triplicate tanks, with oxygen concentration around $95 \%$ air saturation, salinity at $34 \%$ and the controlled photoperiod was set at 16L:8D until 45 days post hatching (dph). Larvae were fed ad libitum with Artemia until $28 \mathrm{dph}$ then with commercial feed (Néo-start, Le Gouessant Aquaculture, France) until $45 \mathrm{dph}$. From $45 \mathrm{dph}$, fish were maintained at $18{ }^{\circ} \mathrm{C}$ and fed a commercial feed (Neo Grower Extra Marin, Le Gouessant Aquaculture, France). From 2 years post-hatching, fish from triplicate tanks were randomly split into duplicate tanks and reared under ambient temperature and natural photoperiod and fed a diet that meets the nutritional requirements of Broodstock (Vitalis Cal, Skretting, Stavanger, Norway). Apart from $\mathrm{pH}$ conditions, F0 fish from the two groups experienced identical experimental conditions throughout their different life stages. To produce a F1 generation, sperm and eggs were collected from 20 males and 6 females of each group. The eggs and sperm from each group were crossed separately to produce F1. The eggs were hatched and the resultant $\mathrm{F} 1$ fish were then maintained in the same $\mathrm{pH}$ condition ( $\mathrm{pH} 8=$ control group; $\mathrm{pH} 7.6=\mathrm{OA}$ group) as their parents. F1 fish from each group were reared in the same condition than F0 at different life stages. Before sampling, fish were fasted for $24 \mathrm{~h}$. For sampling, fish were first lightly anesthetized (20 mg L-1), and then euthanized with a lethal dose (200 mg L-1) of tricaine methanesulfonate 222 (Pharmaq, Fordingbridge, Hampshire, UK). All fish tests were conducted under approved protocols in strict compliance with the EU Directive 2010/63/EU for animal experiments. The present work conforms to the French legal requirements concerning welfare of experimental animals (APAFIS permit no. 17132-2018101614401562).

\section{Cloning of full length cDNA and sequence analysis}

The full length mRNA encoding the sghC1q was cloned from RT-PCR performed on cDNA from whole European sea bass larvae using primers designed on the EST sequence (forward primer: ATGGTCTACACGGTGATTCTC, reverse primer: CTACGACGGGAAGATGAGGA) (Figure 1). After cloning, the sequencing was performed by GENEWIZ service (South Plainfield, USA). The protein sequence deduced from cDNA was obtained using the Expasy translate tool (https://web.expasy.org/translate/). cDNA and deduced protein sequence are available in Genbank nucleotide databasis (MT176417). The amino acid sequences of domains were analysed on SMART (Simple Modular Architecture Research Tool) web resource (http://smart.embl-heidelberg.de/) [57].

A microsynteny analysis consisting in identifying the orthologs of sghC1q gene in other species was performed by determining the flanking genes from European sea bass genome available in Genbank (https://www.ncbi.nlm.nih.gov/assembly/GCA_000689215.1). Blast searches using the mRNA 
sequence as query against European sea bass WGS databases allowed to identify the linking group (i.e. LG14_196, Sequence ID: CBXY010003402.1) containing the sghC1q gene sequence. GENESCAN program (http://argonaute.mit.edu/GENSCAN.html) was next used to locate and identify the flanking genes of sghC1q in European sea bass genome. Orthology assignment was performed by comparing these flanking genes with those of sghC1q genes in other species which genome is available on Ensembl genome browser databasis (https://www.ensembl.org/info/website/index.html). Special attention was focused on the zebrafish sghC1q genes listed by Carland and collaborators [58].

Protein sequences of 25 cerebellin (cbln11) orthologs were obtained on the Genbank databasis (https://www.ncbi.nlm.nih.gov/gene/100149559/ortholog/?scope=186625). GenBank accession numbers for all orthologs are as follows: Danio rerio (NP_001280633.1); Poecilia formosa (XP_016521254.1); Stegastes partitus (XP_008298461.1); Cynoglossus semilaevis (XP_008318068.1); Esox lucius (XP_010864239.1); Clupea harengus (XP_012680903.2); Oreochromis niloticus (XP_013132750.1); Haplochromis burtoni (XP_014185179.1); Cyprinodon variegatus (XP_015260120.1); Sinocyclocheilus grahami (XP_016107579.1); Sinocyclocheilus anshuiensis (XP_016300702.1); Sinocyclocheilus rhinocerous (XP_016366770.1); Pygocentrus nattereri (XP_017570749.1); Oncorhynchus mykiss (XP_021472810.1); Seriola dumerili (XP_022625648.1); Seriola lalandi dorsalis (XP_023271148.1); Salvelinus alpinus (XP_023827263.1); Electrophorus electricus (XP_026878658.1); Denticeps clupeoides (XP_028831622.1); Myripristis murdjan (XP_029931742.1); Salarias fasciatus (XP_029944240.1); Sphaeramia orbicularis (XP_030018732.1); Gadus morhua (XP_030194137.1); Sander lucioperca (XP_031160406.1) and Etheostoma spectabile (XP_032355229.1).

Alignment of European sea bass CBLN11 protein sequence with orthologs from clupeocephala species was performed using MAFFT program in SnapGene ${ }^{\circledR}$ software (Version 4.3).

Phylogenetic reconstruction was performed by aligning CBLN11 protein sequences of clupeocephala species using MAFFT v7.313 in automatic mode [59]. Misaligned regions or with a large number of gaps were trimmed using Gblocks [60] $(-\mathrm{t}=\mathrm{p} ;-\mathrm{p}=\mathrm{n} ;-\mathrm{b} 3=8 ;-\mathrm{b} 4=5 ;-\mathrm{b} 5=\mathrm{h})$ resulting in a total of 93 aligned amino acid sites. Through IQ-TREE [61], the maximum likelihood (ML) estimation of the MLST tree was performed assessing branch supports with a ultrafast bootstrap approximation (1,000 iterations) and a single branch tests (1,000 bootstrap replicates). The WAG model was identified as the best-fitting substitution model according to the BIC criterion using ModelFinder [62]. The phylogenetic tree was drawn using FigTree (http://tree.bio.ed.ac.uk/software/figtree/).

\section{qPCR analysis during larval development and in various adult tissues}

\section{Sampling and RNA extraction}

In order to investigate the cbln11 mRNA expression pattern during larval development, pools (in triplicate) of larvae between 20 and $50 \mathrm{mg}$ (containing five to several dozen individuals depending on the developmental stage) were sampled at five larval stages 13, 19, 26, 33, $45 \mathrm{dph}$. Adult tissues (olfactory rosette, olfactory bulbs, diencephalon, optic tectum, cerebellum, spinal cord gills, heart, muscle, liver, spleen, kidney and proximal intestine) were sampled from three adult males (4 years old). After sampling larvae and adult tissues were transferred into microtubes containing RNAlater (Qiagen, Hilden, Germany) and placed at $4^{\circ} \mathrm{C}$ until total RNA extraction. Protocol of total RNA extraction is the same that previously described [38]. Briefly extraction was performed using Extractall reagent (Eurobio; Courtaboeuf, Essonne, France) combined with Nucleospin RNA column that includes one step of DNase treatment (Macherey-Nagel, Düren, Germany). The concentration and 
quality were determined using an ND-1000 NanoDrop ${ }^{\circledR}$ spectrophotometer (Thermo Scientific Inc., Waltham, MA, USA) and an Agilent Bioanalyzer 2100 (Agilent Technologies Inc., Santa Clara, CA, USA). All samples showed an RNA integrity number (RIN) higher than nine and thus could be used for qPCR analysis. RNA samples were stored at $-80^{\circ} \mathrm{C}$ until use.

\section{Retro-transcription and qPCR analysis}

Retro-transcription (RT) of cDNA for all larval and adult samples was carried out using $500 \mathrm{ng}$ of RNA with an iScript ${ }^{\mathrm{TM}}$ cDNA Synthesis kit (Bio-Rad Laboratories Inc., Hercules, CA, USA) following strictly recommendations from the supplier. RT was performed in duplicate for each RNA sample. Both RT of each sample were next pooled. Negative RT controls were used for all samples (RT reaction without retro-transcriptase enzyme). The analysis of cbln11C1q mRNA for all larval and adult samples was performed by qPCR using the following primers (forward primer: ATGGTCTACACGGTGATTCTC, reverse primer: CTACGACGGGAAGATGAGGA) (Figure 1). The primer pair was designed using Primer 3 plus tool (http://www.bioinformatics.nl/cgibin/primer3plus/primer3plus.cgi). Standard curves were estimated for this primer pair using serial dilutions (from 1/5 to $1 / 40$ ) of both a pool of whole larvae cDNA and cDNA from a mix of different tissues. Efficiency of qPCR ranged was around 100\% with R2 $>0.999$ for both standard curves. Two housekeeping genes [elongation factor 1-alpha (ef1 $\alpha)$ and Ribosomal protein L13a] were tested for normalization of cbln11 mRNA using the following primers: EF1 $\alpha$ forward primer: CTGGAGGGCAGTGAAAAGAT, EF1 $\alpha$ reverse primer: CATCAAGAGCCTCCAGCAGT; L13a forward primer: TCTGGAGGACTGTCAGGGGCATGC, L13a reverse primer: AGACGCACAATCTTGAGAGCAG. Transcript expression was quantified using the CFX96 Touch Real-Time PCR Detection system (Bio-Rad Laboratories Inc.) and the protocol previously described [38]. The relative quantity of messenger was normalized with the $\Delta \Delta \mathrm{Ct}$ method using efl $\alpha$ and Ribosomal protein L13a as reference genes. These reference genes were used as their transcripts have an $\mathrm{M}$ value below 0.5 in our sample sets [63].

A one way ANOVA was used to test significant differences among normalized cbln11 mRNA expression levels. For all analyses, variables were checked for normality (Shapiro test) and equality of variances (Levene test). The level of significance was taken at 0.05 .

\section{qPCR analysis of cbln11 mRNA expression in larvae and olfactory rosette of adult exposed to OA}

RT-qPCR analysis of cbln11 mRNA expression was performed using the protocol as described in the previous section "qPCR analysis during larval development and in various adult tissues in normal conditions". Total RNA was individually extracted in $20 \mathrm{~F} 0$ and $20 \mathrm{~F} 1$ larvae from both control (pH8) and OA (pH7.6) groups at $45 \mathrm{dph}$. Concerning F0 adults fish (4 years old), total RNA of olfactory rosettes were also extracted from 14 individuals from the control group (10 females, 4 males) and 13 individuals from the OA group (6 females, 7 males) at the post-spawning period. Concerning F1 fish at juvenile stage (18 months old), total RNA of olfactory rosettes from $15 \mathrm{~F} 1$ juveniles from each group were sampled. We have ensured the RNA integrity number (RIN) of the extracted RNA were higher than nine before processing to retro-transcription into cDNA and qPCR analysis.

\section{Tissue distribution of $c b \ln 11 \mathrm{mRNA}$ in whole larvae and olfactory rosette by ISH}


Tissue collection

Whole larvae at $45 \mathrm{dph}(\mathrm{n}=3)$ and adult (4 years old) olfactory rosettes $(\mathrm{n}=3)$ were collected from control conditions, fixed overnight at room temperature, dehydrated, embedded in paraffin and cut transversally in series at $6 \mu \mathrm{m}$. All sections were mounted onto poly-L-Lysine-coated slides and keep at $4^{\circ} \mathrm{C}$.

\section{Probes synthesis}

The antisense and sense probes for cbln11 were synthesized by in vitro transcription using pCRIITOPO vector (Invitrogen, Carlsbad, USA) and DIG RNA labelling Kit (Merck, Darmstadt, Germany). The vector containing the full length cbln11 cDNA was linearized by Not1 enzyme before the antisense probe was synthesized by SP6 RNA polymerase. The sense probe used to check for potential unspecific hybridization was obtained using T7 RNA polymerase after linearization of the plasmid by BamH1.

\section{In situ hybridization}

The in situ hybridization protocol was adapted from [64]. The sections were first dewaxed in ClaRal solution (Ral diagnostics, Martillac, France) three times for 7 minutes at room temperature and dehydrated through decreasing concentrations of ethanol. Sections were washed in $0.85 \% \mathrm{NaCl}$ and $1 \mathrm{M}$ phosphate-buffered saline (PBS), $\mathrm{pH} 7.4$, followed by refixation in 4\% paraformaldehyde diluted in PBS for 20 minutes. After two washing steps in PBS for 10 minutes, sections were incubated in proteinase $\mathrm{K}$ for 5 minutes at room temperature $(2 \mu \mathrm{g} / \mathrm{ml}$ in $50 \mathrm{mM}$ Tris-HCl, $\mathrm{pH} 8.0,5 \mathrm{mM}$ EDTA), rinsed and post-fixed for 15 minutes in $4 \%$ paraformaldehyde to block proteinase $\mathrm{K}$ activity. Sections were rinsed twice for 10 minutes in saline-sodium citrate (SSC) $2 \mathrm{X}$ at room temperature. Hybridization was performed overnight at $65^{\circ} \mathrm{C}$ in a humidified chamber using $100 \mu 1$ of hybridization buffer (2X SSC; $2.5 \%$ dextran sulfate; $50 \%$ deionized formamide; 5 X Denhardt's solution; $50 \mu \mathrm{g} / \mathrm{ml}$ of yeast tRNA, pH 8.0; 4 mM EDTA) containing the DIG-labeled cbln11 probe $(1.5 \mu \mathrm{g} / \mathrm{ml})$. On the next day, slides were rinsed in $2 \mathrm{XSSC}$ at $65^{\circ} \mathrm{C}(2 \times 30$ minutes $)$, followed by two rinses at $65^{\circ} \mathrm{C}(2 \times 30$ minutes) in $2 \mathrm{X} \mathrm{SSC} / 50 \%$ formamide. Final rinses were made in 0.2 and $0.1 \mathrm{X} \mathrm{SSC}$ at room temperature (15 minutes each) and sections were processed for immunodetection. The sections were washed for 10 minutes in $100 \mathrm{mM}$ Tris-HCl buffer, $150 \mathrm{mM} \mathrm{NaCl}, \mathrm{pH} 7.5$, and then incubated for 30 minutes in the same buffer containing $0.5 \%$ blocking reagent and $0.1 \%$ Tween. Slides were then incubated overnight at room temperature in alkaline phosphatase-conjugated sheep Fab fragment antibodies to DIG (Roche Diagnostic, Indianapolis, IN) diluted to 1:2000. The next day, sections were rinsed twice (10 minutes) in $100 \mathrm{mM}$ Tris- $\mathrm{HCl}$ buffer, $150 \mathrm{mM} \mathrm{NaCl}, \mathrm{pH} 7.5,0.1 \%$ Tween and incubated ( 3 x 30 minutes) in $100 \mathrm{mM}$ Tris- $\mathrm{HCl}$ buffer, $100 \mathrm{mM} \mathrm{NaCl}, \mathrm{pH} 9.5,0.1 \%$ Tween. The slides were then incubated for fluorescent detection with HNPP (2-hydroxy-3-naphtoic acid-2'phenylanilide phosphate) in HNPP/FastRED solution at room temperature (Roche Diagnostic, Indianapolis, IN) for 2-4 hours. Finally, the slides were rinsed in PBS ( 3 x 5 minutes) before mounting in Vectashield DAPI hard set (Vector laboratories, Burlingame, USA).

\section{Combined cbln11 mRNA in situ hybridization and immunohistochemical detection of tubulin}

To visualize sensory cells of olfactory rosette, a combination of in situ hybridization and immunohistochemistry was performed on the same sections. Cbln11 mRNAs expression was detected by in situ hybridization following protocol described above. The sections were then rinsed twice in PBST (10 min) and immersed in Tris-HCl $50 \mathrm{mM}$ buffer ( $\mathrm{pH} 9.5$ ) for 1 hour at $80^{\circ} \mathrm{C}$ for antigen retrieval, washed twice in PBST (10 min) and subsequently blocked for 45 minutes in $0.2 \%$ Triton PBS (containing $0.5 \%$ dry fat milk) at room temperature before being exposed overnight to the mouse anti-acetylated tubuline (1:100; Acetyl-Tub; clone 6-11B-1; Reference T 6793, Sigma) antibody 
$(1 / 2000)$. On the next day, sections were washed three times in $0.2 \%$ Triton PBS and subsequently incubated with Alexa 488 goat anti-mouse (Invitrogen Molecular Probes, Eugene OR, USA) for $2 \mathrm{~h}$ at room temperature). 


\section{Results}

\section{Sequence analysis of the sghC1q cDNA and protein}

The full-length cDNA of the sghC1q sequence contains an open reading frame (ORF) of 1308 bp encoding a predicted protein of 435 amino acid residues. SMART analysis revealed a potential signal peptide (amino acids 1-17) in the N-terminus, coiled coil region (amino acids 77-228) and a C1q domain (amino acids 300-435) in the C-terminus of sghC1q sequence (Figure 1).

Kelch Like Family Member 33 (klhl33), macrophage mannose receptor ( $m r c)$, FH1/FH2 domain containing protein (fhod) and solute carrier family 12A (slc12a) genes were identified as flanking or neighboring genes to both the sghC1q gene in European sea bass genome and the cbln11 gene in the chromosome 7 of zebrafish genome (Figure 2). Moreover, the fact that CBLN11 is the protein sequence that exhibited in zebrafish the highest scoring BLAST hit (E-value: 2e-28) for the European sea bass sghC1q protein sequence suggests that the present European sea bass $s g h C 1 q$ gene is an ortholog of the zebrafish $c b \ln 11$ gene.

Genbank databasis indicated twenty five orthologs of $c b \ln 11$ gene limited to clupeocephala species. Alignments of the full protein sequences of European sea bass CBLN11 protein with these orthologs revealed that the $\mathrm{C} 1 \mathrm{q}$ domains were conserved among species but otherwise there was a great degree of sequence divergence in size and amino acid composition (Figure 3). In some species (e.g. Cyprinodon variegatus, Poecilia formosa, Sinocyclocheilus anshuiensis, Denticeps clupeoides), CBLN11 sequences are short and do not have a signal peptide and/or coiled coil region.

Our phylogenetic analysis based on the most conserved regions of CBLN11 sequences shows that European sea bass, two cyprinodondiforme and one beryciforme species clustered together and quite separate from other clusters that include different orders of clupeocephala (Figure 4).

\section{mRNA expression profiling during larval development and in adult tissues}

RT-qPCR assays were performed in order to gain insights into the profiling of European sea bass cbln11 mRNA expression during larval development and in different adult tissues under normal conditions. Temporal expression pattern analysis of the cbln11 mRNA during European sea bass larvae development revealed very low relative expression levels until 26 dph then an exponential increase between $26 \mathrm{dph}$ and $45 \mathrm{dph}$ (Figure 5). In adult, cbln11 mRNA is mainly expressed in the olfactory rosette and in the gills and low expression levels are also detected in the muscle, heart and in the different parts of the central nervous system (Figure 6). No significant amplification signal was detected in the spleen, kidney, intestine and liver.

\section{Tissue distribution of cbln11 mRNA in whole larvae and olfactory rosette}

Riboprobe to cbln11 mRNA was used for ISH in the olfactory rosette of European sea bass. The expression pattern of the cbln11 mRNA was systematically observed in all individuals analysed. The specificity of the hybridization signal obtained was confirmed by absence of labelling in the negative control slides incubated with the sense probe. At larval stage, hybridization labelling was only observed in the apical part of the forming olfactory lamellae constituting the rosette (Figure $7 \mathrm{~A}$ ). At adult stage, double-label RNA ISH experiments using a mouse anti-acetylated tubulin antibody 
(Acetyl-Tub; clone, 6-11B-1; Reference T 6793, Sigma) as a marker of neurons revealed a high expression of the cbln11 mRNA in non-neuron cells lining the non-sensory epithelium at the basal and the apical parts of the olfactory lamellae (Figure 7 B-D). The labelling was detected in the majority of cells bordering the surface of the non-sensory epithelium. Specificity of the hybridization signal was demonstrated by the absence of labelling with the control sense probe (Figure $7 \mathrm{E}, \mathrm{F}$ ).

\section{qPCR analysis of cbln11 mRNA expression in larvae and olfactory rosette of adult exposed to} OA

The 45-day-old larvae from the F0 generation showed 1.85 lower cbln11 mRNA level in OA condition compared to control condition (Figure 8 a, $\mathrm{P}=0.0002$ ). Inversely, cbln11 mRNA level was significantly higher (x1.98) four years later in the olfactory rosette of adult fish (F0) exposed to OA compared to control group (Figure $8 \mathrm{~b}, \mathrm{P}=0.02$ ). Higher cbln11 mRNA level was also observed in whole larvae at $45 \mathrm{dph}$ (Figure $8 \mathrm{c}, \mathrm{x} 1.57$, one-way ANOVA, $\mathrm{P}=0.00002$ ) as well as in the olfactory rosette of juveniles from the $\mathrm{F} 1$ exposed to $\mathrm{OA}$ (Figure $8 \mathrm{~d}$, x1.95, $\mathrm{P}=0.03$ ). 


\section{Discussion}

We characterized for the first time in European sea bass the transcript and the deduced protein sequence of a member of C1qDC family. Based on the organization of the protein sequence which includes a leading signal peptide, a coiled coil region and a C1q domain, it may be classified as a member of sghC1q subgroup defined by Carland and collaborators [44] or within the C1q-like type 2 subfamily as defined by Gerdol and collaborators [47]. Interestingly, our microsynteny analysis revealed that this European sea bass sghC1q gene is the ortholog of zebrafish cbln11 gene. In zebrafish, cbln11 gene is located on chromosome 7, in a large DNA distance from 3 other clustered sghC1q genes (sghC1q16, sghC1q6 and sghC1q8) [58]. In total, twenty sghC1q genes have been identified and located in the genome of zebrafish [58]. A global synteny analysis dedicated on sghC1q genes in European sea bass will be necessary to determine if the two species share the same genomic organization of sghC1q genes. Interestingly, orthologs of $c b l n 11$ gene have only been identified in clupeocephala species. Additional in-depth studies will be necessary to confirm that other teleost species such as anguilliformes or osteoglossiformes orders and other vertebrate species including mammals really lack $c b \ln 11$ gene orthologs.

To our knowledge, there is no clear information in the literature regarding cbln11 gene function. However, interestingly two studies based on the transcriptomic analysis of whole zebrafish larvae revealed that cbln11 gene expression was up-expressed in animals infected by bacteria suggesting that this gene may be involved in pathogen defense-associated pathways $[65,66]$. This role would be in agreement with the known antibacterial and immuno-regulatory properties of several C1qDC proteins in marine organisms including fish species [49-52, 67]. Our alignment data indicated that the C1q domain known to be involved in target binding and formation or stabilization of the hydrophobic core of the $\mathrm{gC} 1 \mathrm{q}$ structure is relatively well conserved among CBLN11 orthologs [44, 54, 68]. This data suggests that this C1q domain might play important roles in CBLN11 activity. However, CBLN11 function may be divergent among the clupeocephala species given the differences of sequence (i.e. lack of signal peptide, heterogeneity of coiled coil region) observed among orthologs.

There is very limited information related to cbln11 gene expression available in the literature and databases. GEO Profiles on NCBI databasis indicates that cbln11 mRNA expression has been observed by microarray experiments in the heart, retina and brain of zebrafish but without any information on relative abundances of the transcript among the tissues. In the present study, we found by qPCR analysis that cbln11 mRNA was mainly expressed in the olfactory rosette and in the gills of adult sea bass. Low expression was also observed in the skeletal muscle, heart and in the different parts of the central nervous system while no expression was detected in the liver, spleen, kidney or intestine. According to that, cbln11 mRNA was also shown to be not expressed in the liver of zebrafish [58]. In half-smooth tongue sole (Cynoglossus semilaevis) and in black rockfish (Sebastes schlegelii), sghC1q mRNA was shown to be widely expressed throughout all the tested tissues including immune related organs such as spleen and kidney with highest expression detected in the liver $[51,52]$. The fact that $c b \ln 11$ mRNA expression profile differs from that observed for sghC1q genes in half-smooth tongue sole and in black rockfish suggests that these genes are not orthologs to Cbln11 gene. While sghC1q mRNA expression was detected in the gills of these former species, the present study is, to our knowledge, one of the first to reveal the expression of a C1qDC protein in the peripheral olfactory organ. One previous study only mentioned the presence of an EST coding for a protein containing a $\mathrm{C} 1 \mathrm{Q}$ and collagen domain in the olfactory epithelium transcriptome of the goldfish (Carassius auratus) [69]. 
In European sea bass, the peripheral olfactory organ contains a rosette consisting of about forty lamellae covered by the olfactory epithelium [70]. The olfactory lamellae are gradually raised in the olfactory cavity during European sea bass larval development [70]. The exponential pattern of cbln11 mRNA expression observed during larval development in the present study may be associated to the development of olfactory epithelium. The olfactory epithelium, in European sea bass as in other fish species, includes sensory and non-sensory areas [71]. In European sea bass, the sensory epithelium consists mainly in bipolar neurons, ciliated non-sensory cells, rod cells and rodlet cells while the nonsensory epithelium is mainly made up of microridge cells, and also goblet cells and ciliated nonreceptor cells. The sensory epithelium is located in the flat surfaces of the lamellae while the nonsensory epithelium occupies the basal and the apical parts of the olfactory lamellae [70]. In the present study, cbln11 mRNA expression was shown to be expressed in non-neural cells lining the non-sensory epithelium at the basal and the apical parts of the olfactory lamellae, and more specifically in the microridge cells and possibly in goblet cells based on the uniform labelling distribution on the epithelial surface. This data indicates that CBLN11 protein contrary to C1q-like protein is not directly involved in the synapse organization of neuronal cells and in the olfactory sensory pathway. Considering the potential role played by $c b \ln 11$ gene in the defense against pathogens we can hypothesize that CBLN11 protein may be secreted by the epithelial cells in the mucosal non-sensory epithelium of olfactory rosette to participate to the antipathogenic response. According to that, Sepahi and collaborators [72] localized immune cells in the non-sensory mucosal epithelium at the top of each olfactory lamella in rainbow trout (Oncorhynchus mykiss). Additional histological analysis using marker of immune cells would be necessary to confirm a putative expression of cbln11 mRNA in cells involved in immune response. Moreover, it would be necessary to evaluate this cbln11 mRNA expression after bacterial or viral infection. The analysis of antibacterial and antiviral properties of CBLN11 will definitely reveal the implication of the protein in antipathogen responses. Similar investigation in the gills could also reveal comparable function of the cbln11gene in another epithelial tissue.

An important finding in the current study was the OA-induced effect on cbln11 mRNA levels in the whole larvae as well as in the olfactory rosette of European sea bass. Interestingly, our data revealed significant lower quantities of cbln11 mRNA levels in the whole F0 larvae 45 days after the beginning of the exposure to the OA. The early OA-induced significant decrease in cbln11 mRNA contrast with the OA-induced significant increase levels observed four years later at adult stage in the same population. Since our ISH analysis revealed that $c b \ln 11$ mRNA labelling was restricted to olfactory rosette, we assume that the regulation observed at larval stage mainly occurred in this tissue. One hypothesis explaining the opposite effects of OA on cbln11 mRNA expression levels in F0 may be a differential susceptibility to OA between larval and adult stages. Indeed, previous data obtained in marine organisms indicate that susceptibility to OA may be variable among different life stages [73, 74]. However, this hypothesis may be rebutted since cbln11 mRNA was also shown to be significantly higher at both larval and juvenile stages in individuals from the F1 generation exposed to OA compared to control group. A second explanation for the lower levels of cbln 11 mRNA expression in F0 larvae exposed to OA could be a delay in the process of olfactory rosette development. Indeed, we showed in the present study that cbln11 mRNA levels gradually increased during normal larval development. Time-course histological analysis of olfactory rosette development combined with investigation of other genes expressed in this tissue (e.g. olfactory marker proteins) would allow to confirm this hypothesis. Finally, the third hypothesis explaining the different OA-induced effects on cbln11 mRNA levels between larval and adult stage in F0 generation may be related to the duration of exposure. Contrary to what has been shown for other environmental constraints such as hypoxia [75], very few studies to our knowledge mention an effect of lifetime exposure to OA on the physiological 
response in fish species [38]. On the opposite, studies in fish indicate that the impact of OA on behavior persists regardless of the duration of exposure [11,37]. However, it is now admitted that duration of exposure to environmental constraint may modify epigenetic state (i.e. modification of DNA and histones) of a genome which may interact with environmental and developmental factors to influence the gene expression [76, 77]. Thus, the within-life different cbln11 mRNA expression response to OA observed in the present study may result from the complex interaction among factors [Gene x (Environment + Epigenetic) x Development x Stochasticity] which underlie developmental phenotypic plasticity [78]. Kinetic investigation of epigenetic regulation on olfactory rosette genome during the exposure of European sea bass to OA would allow to confirm this hypothesis. Interestingly, the present study reveals that similar higher expression of cbln11 mRNA expression persisted in larvae from F1 exposed to OA compared to control group. This data thus suggests no transgenerational acclimation of cbln11 mRNA expression. This lack of transgenerational acclimation contrasts with data obtained in anemonefish Amphiprion melanopus in which effects of OA on the metabolic rate, growth and survival of juvenile were absent or reversed when their parents were reared under similar OA condition [40].

In conclusion, we identified and characterized the cbln11 gene from European sea bass and revealed for the first time in fish that its transcript is expressed in the non-sensory epithelium of olfactory rosette. While the functional role of CBLN11 protein still needs to be determined, there is a strong case it is involved in immune responses within the nasal mucosa of European sea bass. The regulation of mRNA expression following OA could reflect the implication of cbln11 gene in the defense system involved in the protection against the danger that represents a lower $\mathrm{pH}$ [79]. Whether the upregulation of cbln11 mRNA expression under OA observed in the present study is associated with higher protein level and with modification of immune function and defense capacities against pathogen remains to be explored. To our knowledge, contrary to numerous studies performed in invertebrates [80-84], only few studies in fish mentioned a plastic response of defense system to ocean acidification $[32,85]$. This kind of evidence would provide valuable information on the impact of OA on fish fitness.

\section{Acknowledgments}

We wish to thank Dr Lucile Durand-Le Rolland from Laboratory of Microbiology of the Extreme Environments (UMR 6197 IFREMER/UBO/CNRS) for microscopic analysis. This work was supported by LabexMer (ANR-10LABX-0019,OASYS project), the Ministry of Ecological and Solidarity Transition and the Foundation for Biodiversity Research (Ocean Acidification Program, PACIO project) and the Deutsche Forschungemeinschaft, PE 1157/8-1, MA4271/3-1 (the FITNESS project). 


\section{Legends}

Figure 1: Nucleotide and deduced amino acid sequences of the full length coding region of cbln11 gene. The amino acids are shown as single-letter codes above the nucleotide sequence. The signal peptide, the coiled coil region and the globular C1q domain revealed by SMART analysis (http://smart.embl-heidelberg.de/) are boxed in white, grey and black, respectively. Primers used for $R T-P C R$ cloning of the full length $C D N A$ and qPCR analysis are underlined using $\left(\_\right)$and $\left(\_\right)$ respectively.

Figure 2: Identification of European sea bass cbln11 gene by microsynteny analysis. Flanking genes of cbln11 gene are partially conserved between European sea bass and zebrafish (Danio rerio). Genomic sequence including European sea bass cbln11 gene is originated from Genbank databasis (GenBank: CBXY010003402.1). Zebrafish cbln11 gene is located on chromosome (Chr) 7 (LOC103911323). Fhod1l and 3l: FH1/FH2 domain-containing protein 1 and 3 like; Mrc1 and 2: Macrophage mannose receptor 1 and 2; Klhl33: Kelch Like Family Member 33; Slc12a3 and 10.2: Solute Carrier family 12 member3 and 10 tandem duplicate 2; Parp14: Poly [ADP-ribose] polymerase 14 .

Figure 3: Protein sequence alignment of European sea bass CBLN11 and its orthologs from clupeocephala species performed using MAFFT program and visualized using SnapGene ${ }^{\circledR}$ software (Version 4.3). Amino acids are color highlighted based on properties and conservation (Clustal X Default Colouring) and gaps are indicated by a dash line. Signal peptide (blue), coiled coil region (green), and globular C1q domain (red) of European sea bass CBLN11 are indicated in blue, green and red boxes, respectively. A consensus sequence including residues with a conservation threshold of $50 \%$ among orthologs is indicated on the upper part of the alignment. The sequence conservation among species is illustrated by gray blocks. The lengths of the sequences are indicated at the Cterminal ends.

Figure 4: Phylogenetic analysis of CBLN11 orthologs. The phylogenetic tree was constructed using IQ-TREE. European sea bass CBLN11 protein (MT176417) is indicated by a black arrow. Numbers on each node indicate the length of the branch and the frequency of occurrence from 100 bootstraps. The accession numbers of the analysed sequences were as follows: Danio rerio (NP_001280633.1); Poecilia formosa (XP_016521254.1); Stegastes partitus (XP_008298461.1); Cynoglossus semilaevis (XP_008318068.1); Esox lucius (XP_010864239.1); Clupea harengus (XP_012680903.2); Oreochromis niloticus (XP_013132750.1); Haplochromis burtoni (XP_014185179.1); Cyprinodon variegatus (XP_015260120.1); Sinocyclocheilus grahami (XP_016107579.1); Sinocyclocheilus anshuiensis (XP_016300702.1); Sinocyclocheilus rhinocerous (XP_016366770.1); Pygocentrus nattereri (XP_017570749.1); Oncorhynchus mykiss (XP_021472810.1); Seriola dumerili (XP_022625648.1); Seriola lalandi dorsalis (XP_023271148.1); Salvelinus alpinus (XP_023827263.1); Electrophorus electricus (XP_026878658.1); Denticeps clupeoides (XP_028831622.1); Myripristis murdjan (XP_029931742.1); Salarias fasciatus (XP_029944240.1); Sphaeramia orbicularis (XP_030018732.1); Gadus morhua (XP_030194137.1); Sander lucioperca (XP_031160406.1) and Etheostoma spectabile (XP_032355229.1). 
Figure 5: Relative expression profiles of cbln11 mRNA during development of European sea bass as determined by qRT-PCR assay. Relative expression levels were normalized by Ef1alpha and Ribosomal Protein L13a mRNA levels. Values are means of the normalized expression. Bars represent $+/$ - standard deviation $(n=3$ ). Significant differences in expression levels (one-way ANOVA with 0.05 confidence interval and Fisher post-hoc test) between groups are indicated with letters.

Figure 6: RT-qPCR analysis of cbln11 mRNA expression in various European sea bass tissues. Bars represent standard deviation $(n=3)$. Relative expression levels were normalized by Ef1alpha and Ribosomal Protein L13a mRNA levels.

Figure 7: Localization of cbln11 mRNA in olfactory rosette of European sea bass. A: in situ hybridization using cbln11 mRNA antisense probe was performed on tissue sections of whole European sea bass larvae at 45dph. cbln11 mRNA labelling (arrowheads) was only detected in cells mainly located in the apical part of epithelium in the olfactory rosette (OR). The same section shows the localization of cell nuclei stained in blue by DAPI. The B-D, Double-label RNA in situ hybridizations coupled with immunofluorescence were performed on tissue sections of adult European sea bass olfactory rosette. In addition to cbln11 mRNA probe (red labelling), a mouse anti-acetylated tubulin antibody was used as marker of neuron cells (green labelling). Cell nuclei were stained by DAPI (blue labelling). B, C, cbln11 mRNA (arrowheads) is expressed in non-neuron cells lining the non-sensory epithelium at the apical part of the olfactory lamellae. Asterisk: Goblet cells. D, highermagnification view of the separation between sensory and non-sensory epithelium in the apical part of the olfactory lamellae. $d$, cbln11 mRNA (arrowheads) is expressed in a population of non-neuron cells lining the non-sensory epithelium (nse) at the basal part of the olfactory lamellae. E, F, Hybridization signal obtained with cbln11 antisense (E) and Sense control $(F)$ probe in the basal part of olfactory lamellae demonstrating the specificity of the labelling. Asterisk: Goblet cells. $n$, neurons; LP, lamina propria; nc: nasal cavity. Scale bars: $100 \mu \mathrm{m}$.

Figure 8: Effect of OA on cbln11 mRNA expression level in a- larvae (45dph) from F0 ( $n=20), b$ olfactory rosette in adult (4 years old) from F0 ( $n=14$ for control group and $n=13$ for OA group), $c$ larvae (45 dph) from F1 $(n=20)$ and d- olfactory rosette in juvenile (18 months old) from F1 $(n=15)$. Relative expression levels were measured by RT-qPCR analysis and normalized by Ef1alpha and Ribosomal Protein L13a mRNA levels. Asterisk indicates significant differences in expression levels between control ( $p H 8)$ and OA (pH7.6) conditions (one-way ANOVA with 0.05 confidence interval). 
References

1. Doney, S.C., et al., Climate change impacts on marine ecosystems. Ann Rev Mar Sci, 2012. 4: p. 11-37.

2. Olsen, E., et al., Ocean Futures Under Ocean Acidification, Marine Protection, and Changing Fishing Pressures Explored Using a Worldwide Suite of Ecosystem Models. Frontiers in Marine Science, 2018. 5(64).

3. Pörtner, H.-O., Ecosystem effects of ocean acidification in times of ocean warming: A physiologist's view. Marine Ecology-progress Series - MAR ECOL-PROGR SER, 2008. 373: p. 203-217.

4. Branch, T.A., et al., Impacts of ocean acidification on marine seafood. Trends Ecol Evol, 2013. 28(3): p. 178-86.

5. Clements, J.C. and H.L. Hunt, Effects of CO2-driven sediment acidification on infaunal marine bivalves: A synthesis. Mar Pollut Bull, 2017. 117(1-2): p. 6-16.

6. Claiborne, J.B., et al., A mechanism for branchial acid excretion in marine fish: identification of multiple $\mathrm{Na}+\mathrm{H}+$ antiporter (NHE) isoforms in gills of two seawater teleosts. J Exp Biol, 1999. 202(Pt 3): p. 315-24.

7. Claiborne, J.B., S.L. Edwards, and A.I. Morrison-Shetlar, Acid-base regulation in fishes: cellular and molecular mechanisms. J Exp Zool, 2002. 293(3): p. 302-19.

8. Heuer, R.M. and M. Grosell, Physiological impacts of elevated carbon dioxide and ocean acidification on fish. Am J Physiol Regul Integr Comp Physiol, 2014. 307(9): p. R1061-84.

9. Esbaugh, A.J., Physiological implications of ocean acidification for marine fish: emerging patterns and new insights. Journal of Comparative Physiology B, 2018. 188(1): p. 1-13.

10. Ashur, M.M., N.K. Johnston, and D.L. Dixson, Impacts of Ocean Acidification on Sensory Function in Marine Organisms. Integr Comp Biol, 2017. 57(1): p. 63-80. doi: 10.1093/icb/icx010.

11. Munday, P.L., et al., Behavioural impairment in reef fishes caused by ocean acidification at CO2 seeps. Nature Climate Change, 2014. 4(6): p. 487-492.

12. Munday, P.L., et al., Ocean acidification impairs olfactory discrimination and homing ability of a marine fish. Proc Natl Acad Sci U S A, 2009. 106(6): p. 1848-52.

13. Rossi, T., et al., Lost at sea: ocean acidification undermines larval fish orientation via altered hearing and marine soundscape modification. Biology Letters, 2016. 12(1).

14. Nilsson, G.E., et al., Near-future carbon dioxide levels alter fish behaviour by interfering with neurotransmitter function. Nature Climate Change, 2012. 2(3): p. 201-204.

15. Forsgren, E., et al., Elevated $\mathrm{CO} 2$ affects embryonic development and larval phototaxis in a temperate marine fish. Ecology and Evolution, 2013. 3(11): p. 3637-3646.

16. Clark, T., et al., Ocean acidification does not impair the behaviour of coral reef fishes. Nature, 2020. 577: p. 1-6.

17. Strobel, A., et al., Elevated temperature and PCO2 shift metabolic pathways in differentially oxidative tissues of Notothenia rossii. Comp Biochem Physiol B Biochem Mol Biol, 2013. 166(1): p. 48-57.

18. Strobel, A., et al., Metabolic shifts in the Antarctic fish Notothenia rossii in response to rising temperature and PCO2. Front Zool, 2012. 9(1): p. 28.

19. Bignami, S., et al., Ocean acidification alters the otoliths of a pantropical fish species with implications for sensory function. Proc Natl Acad Sci U S A, 2013. 110(18): p. 7366-70.

20. Checkley, D.M., Jr., et al., Elevated CO2 enhances otolith growth in young fish. Science, 2009. 324(5935): p. 1683.

21. Coll-Llado, C., et al., Ocean acidification promotes otolith growth and calcite deposition in gilthead sea bream (Sparus aurata) larvae. Sci Rep, 2018. 8(1): p. 8384.

22. Di Franco, A., et al., Ocean acidification affects somatic and otolith growth relationship in fish: evidence from an in situ study. Biol Lett, 2019. 15(2): p. 20180662. 
23. Holmberg, R.J., et al., Ocean acidification alters morphology of all otolith types in Clark's anemonefish (Amphiprion clarkii). PeerJ, 2019. 7: p. e6152.

24. Perry, D.M., et al., Effect of ocean acidification on growth and otolith condition of juvenile scup, Stenotomus chrysops. Ecol Evol, 2015. 5(18): p. 4187-96.

25. Pimentel, M.S., et al., Defective skeletogenesis and oversized otoliths in fish early stages in a changing ocean. J Exp Biol, 2014. 217(Pt 12): p. 2062-70.

26. Faria, A.M., et al., Reproductive trade-offs in a temperate reef fish under high pCO2 levels. Mar Environ Res, 2018. 137: p. 8-15.

27. Milazzo, M., et al., Ocean acidification affects fish spawning but not paternity at $\mathrm{CO} 2$ seeps. Proc Biol Sci, 2016. 283(1835).

28. Servili, A., et al., Climate change impacts on fish reproduction are mediated at multiple levels of the brain-pituitary-gonad axis. Gen Comp Endocrinol, 2020. 291: p. 113439.

29. Cline, A.J., S.L. Hamilton, and C.A. Logan, Effects of multiple climate change stressors on gene expression in blue rockfish (Sebastes mystinus). Comp Biochem Physiol A Mol Integr Physiol, 2020. 239: p. 110580.

30. Porteus, C.S., et al., Near-future $\mathrm{CO} 2$ levels impair the olfactory system of a marine fish. Nature Climate Change, 2018. 8(8): p. 737-+.

31. Huth, T.J. and S.P. Place, RNA-seq reveals a diminished acclimation response to the combined effects of ocean acidification and elevated seawater temperature in Pagothenia borchgrevinki. Mar Genomics, 2016. 28: p. 87-97.

32. Bresolin de Souza, K., et al., Effects of increased $\mathrm{CO} 2$ on fish gill and plasma proteome. PLoS One, 2014. 9(7): p. e102901.

33. Maneja, R.H., et al., The proteome of Atlantic herring (Clupea harengus L.) larvae is resistant to elevated pCO2. Mar Pollut Bull, 2014. 86(1-2): p. 154-160.

34. Silva, C.S.E., et al., Sand smelt ability to cope and recover from ocean's elevated CO2 levels. Ecotoxicol Environ Saf, 2018. 154: p. 302-310.

35. Parker, L., et al., Adult exposure influences offspring response to ocean acidification. Global Change Biology, 2012. 18: p. 82-92.

36. Murray, C.S., et al., Offspring sensitivity to ocean acidification changes seasonally in a coastal marine fish. Marine Ecology Progress Series, 2014. 504: p. 1-11.

37. Munday, P.L., et al., Elevated CO2 affects the behavior of an ecologically and economically important coral reef fish. Marine Biology, 2013. 160(8): p. 2137-2144.

38. Mazurais, D., et al., Long-term exposure to near-future ocean acidification does not affect the expression of neurogenesis- and synaptic transmission-related genes in the olfactory bulb of European sea bass (Dicentrarchus labrax). J Comp Physiol B, 2020. 190(2): p. 161-167.

39. Welch, M., et al., Effects of elevated CO2 on fish behaviour undiminished by transgenerational acclimation. Nature Climate Change, 2014. 4.

40. Miller, G., et al., Parental environment mediates impacts of elevated $\mathrm{CO} 2$ on a coral reef fish. Nature Climate Change, 2012. 2: p. 858-861.

41. Cominassi, L., et al., Combined effects of ocean acidification and temperature on larval and juvenile growth, development and swimming performance of European sea bass (Dicentrarchus labrax). PLoS One, 2019. 14(9): p. e0221283.

42. Cominassi, L., et al., Food availability modulates the combined effects of ocean acidification and warming on fish growth. Sci Rep, 2020. 10(1): p. 2338.

43. Crespel, A., et al., The development of contemporary European sea bass larvae (Dicentrarchus labrax) is not affected by projected ocean acidification scenarios. Marine Biology, 2017. 164(7).

44. Carland, T.M. and L. Gerwick, The C1q domain containing proteins: Where do they come from and what do they do? Dev Comp Immunol, 2010. 34(8): p. 785-90.

45. Hu, Y.L., et al., Characterization of C1q in Teleosts INSIGHT INTO THE MOLECULAR AND FUNCTIONAL EVOLUTION OF C1q FAMILY AND CLASSICAL PATHWAY. Journal of Biological Chemistry, 2010. 285(37): p. 28777-28786. 
46. Mei, J. and J. Gui, Bioinformatic identification of genes encoding C1q-domain-containing proteins in zebrafish. J Genet Genomics, 2008. 35(1): p. 17-24.

47. Gerdol, M., P. Venier, and A. Pallavicini, The genome of the Pacific oyster Crassostrea gigas brings new insights on the massive expansion of the C1q gene family in Bivalvia. Dev Comp Immunol, 2015. 49(1): p. 59-71.

48. McDowell, I.C., et al., Multi-species protein similarity clustering reveals novel expanded immune gene families in the eastern oyster Crassostrea virginica. Fish Shellfish Immunol, 2016. 53: p. 13-23.

49. Wang, L., et al., A C1q domain containing protein from scallop Chlamys farreri serving as pattern recognition receptor with heat-aggregated IgG binding activity. PLoS One, 2012. 7(8): p. e43289.

50. Wang, L., et al., A novel C1qDC protein acting as pattern recognition receptor in scallop Argopecten irradians. Fish Shellfish Immunol, 2012. 33(2): p. 427-35.

51. Du, X., et al., A novel C1q domain containing protein in black rockfish (Sebastes schlegelii) serves as a pattern recognition receptor with immunoregulatory properties and possesses binding activity to heat-aggregated IgG. Fish Shellfish Immunol, 2019. 87: p. 73-81.

52. Zeng, Y., et al., sghC1q, a novel C1q family member from half-smooth tongue sole (Cynoglossus semilaevis): identification, expression and analysis of antibacterial and antiviral activities. Dev Comp Immunol, 2015. 48(1): p. 151-63.

53. Yuzaki, M., Synapse formation and maintenance by C1q family proteins: a new class of secreted synapse organizers. Eur J Neurosci, 2010. 32(2): p. 191-7.

54. Kishore, U. and K.B.M. Reid, C1q: Structure, function, and receptors. Immunopharmacology, 2000. 49(1): p. 159-170.

55. Solomon, S., et al., Distinct structural features of caprin-1 mediate its interaction with G3BP-1 and its induction of phosphorylation of eukaryotic translation initiation factor 2alpha, entry to cytoplasmic stress granules, and selective interaction with a subset of mRNAs. Mol Cell Biol, 2007. 27(6): p. 2324-42.

56. Stocker, T.F., et al., Climate change 2013: The physical science basis. Contribution of working group I to the fifth assessment report of the intergovernmental panel on climate change, 2013. 1535.

57. Letunic, I. and P. Bork, 20 years of the SMART protein domain annotation resource. Nucleic Acids Research, 2017. 46(D1): p. D493-D496.

58. Carland, T.M., et al., Differential expression and intrachromosomal evolution of the sghC1q genes in zebrafish (Danio rerio). Dev Comp Immunol, 2012. 36(1): p. 31-8.

59. Katoh, K. and D.M. Standley, MAFFT multiple sequence alignment software version 7: improvements in performance and usability. Mol Biol Evol, 2013. 30(4): p. 772-80.

60. Castresana, J., Selection of conserved blocks from multiple alignments for their use in phylogenetic analysis. Mol Biol Evol, 2000. 17(4): p. 540-52.

61. Nguyen, L.T., et al., IQ-TREE: a fast and effective stochastic algorithm for estimating maximum-likelihood phylogenies. Mol Biol Evol, 2015. 32(1): p. 268-74.

62. Kalyaanamoorthy, S., et al., ModelFinder: fast model selection for accurate phylogenetic estimates. Nature Methods, 2017. 14(6): p. 587-589.

63. Vandesompele, J., et al., Accurate normalization of real-time quantitative RT-PCR data by geometric averaging of multiple internal control genes. Genome Biol, 2002. 3(7): p. Research0034.

64. Escobar, S., et al., Expression of kisspeptins and kiss receptors suggests a large range of functions for kisspeptin systems in the brain of the European sea bass. PLoS One, 2013. 8(7): p. e70177.

65. Torraca, V., et al., Shigella sonnei infection of zebrafish reveals that O-antigen mediates neutrophil tolerance and dysentery incidence. PLoS Pathog, 2019. 15(12): p. e1008006.

66. Saraceni, P.R., et al., Zebrafish (Danio Rerio) as Infection Model to Study the Pathogenesis of Bacteria Aeromonas Hydrophila: Doctoral Dissertation. 2017: Universidade de Vigo. 
67. Gerwick, L., W.S. Reynolds, and C.J. Bayne, A precerebellin-like protein is part of the acute phase response in rainbow trout, Oncorhynchus mykiss. Dev Comp Immunol, 2000. 24(6-7): p. 597-607.

68. Kishore, U., et al., $\mathrm{C} 1 \mathrm{q}$ and tumor necrosis factor superfamily: modularity and versatility. Trends Immunol, 2004. 25(10): p. 551-61.

69. Kolmakov, N.N., et al., Analysis of the goldfish Carassius auratus olfactory epithelium transcriptome reveals the presence of numerous non-olfactory GPCR and putative receptors for progestin pheromones. BMC genomics, 2008. 9: p. 429-429.

70. Diaz, J.P., et al., Ultrastructural study of the olfactory organ in adult and developing European sea bass, Dicentrarchus labrax. Canadian Journal of Zoology, 2002. 80: p. 1610-1622.

71. Hansen, A. and B.S. Zielinski, Diversity in the olfactory epithelium of bony fishes: development, lamellar arrangement, sensory neuron cell types and transduction components. J Neurocytol, 2005. 34(3-5): p. 183-208.

72. Sepahi, A., et al., Tissue Microenvironments in the Nasal Epithelium of Rainbow Trout (Oncorhynchus mykiss) Define Two Distinct CD8alpha+ Cell Populations and Establish Regional Immunity. J Immunol, 2016. 197(11): p. 4453-4463.

73. Kroeker, K.J., et al., Impacts of ocean acidification on marine organisms: quantifying sensitivities and interaction with warming. Global Change Biology, 2013. 19(6): p. 1884-1896.

74. Ross, P., et al., The Impact of Ocean Acidification on Reproduction, Early Development and Settlement of Marine Organisms. Water, 2011. 3: p. 1005-1030.

75. Spicer, J., Stressors in the Marine Environment: Physiological and ecological responses; societal implications. 2016, Oxford: Oxford University Press. 384.

76. Burggren, W., Epigenetic Inheritance and Its Role in Evolutionary Biology: Re-Evaluation and New Perspectives. Biology (Basel), 2016. 5(2).

77. Skinner, M.K., Environmental Epigenetics and a Unified Theory of the Molecular Aspects of Evolution: A Neo-Lamarckian Concept that Facilitates Neo-Darwinian Evolution. Genome Biol Evol, 2015. 7(5): p. 1296-302.

78. Burggren, W.W., Phenotypic Switching Resulting From Developmental Plasticity: Fixed or Reversible? Front Physiol, 2019. 10: p. 1634.

79. Fuchs, E.J. and P. Matzinger, Is cancer dangerous to the immune system? Seminars in Immunology, 1996. 8(5): p. 271-280.

80. Cao, R., et al., CO2-induced ocean acidification impairs the immune function of the Pacific oyster against Vibrio splendidus challenge: An integrated study from a cellular and proteomic perspective. Sci Total Environ, 2018. 625: p. 1574-1583.

81. Sun, T., et al., Seawater acidification induced immune function changes of haemocytes in Mytilus edulis: a comparative study of CO2 and HCl enrichment. Sci Rep, 2017. 7: p. 41488.

82. Leite Figueiredo, D.A., et al., Ocean acidification affects parameters of immune response and extracellular $\mathrm{pH}$ in tropical sea urchins Lytechinus variegatus and Echinometra luccunter. Aquat Toxicol, 2016. 180: p. 84-94.

83. Castillo, N., et al., Ocean acidification and pathogen exposure modulate the immune response of the edible mussel Mytilus chilensis. Fish Shellfish Immunol, 2017. 70: p. 149-155.

84. Migliaccio, O., et al., Living in future ocean acidification, physiological adaptive responses of the immune system of sea urchins resident at a CO2 vent system. Sci Total Environ, 2019. 672: p. 938-950.

85. Bresolin de Souza, K., et al., Increased activity of lysozyme and complement system in Atlantic halibut exposed to elevated CO2 at six different temperatures. Mar Environ Res, 2016. 122: p. 143-147. 


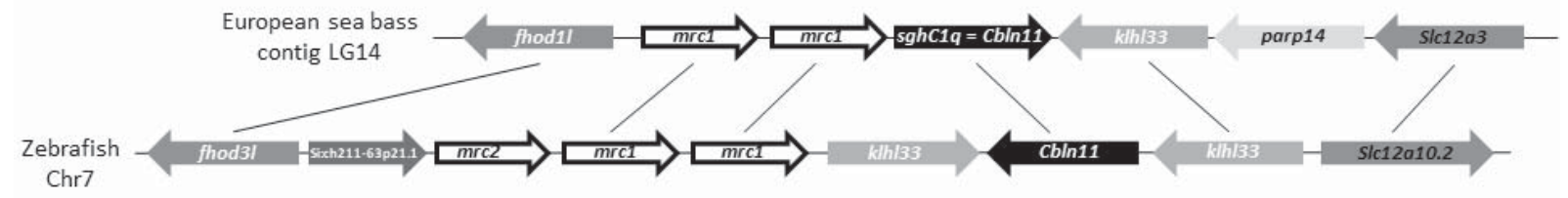



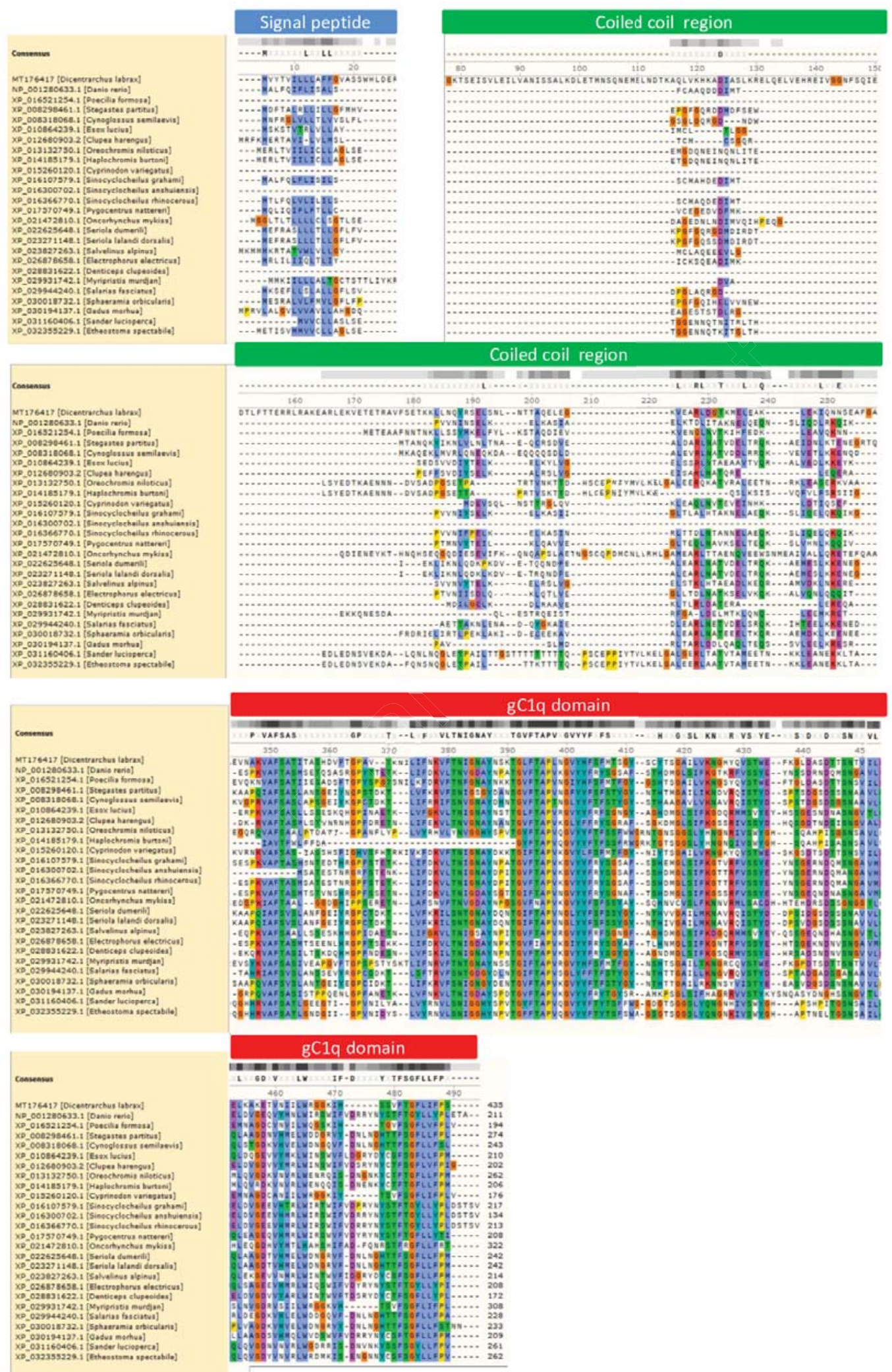


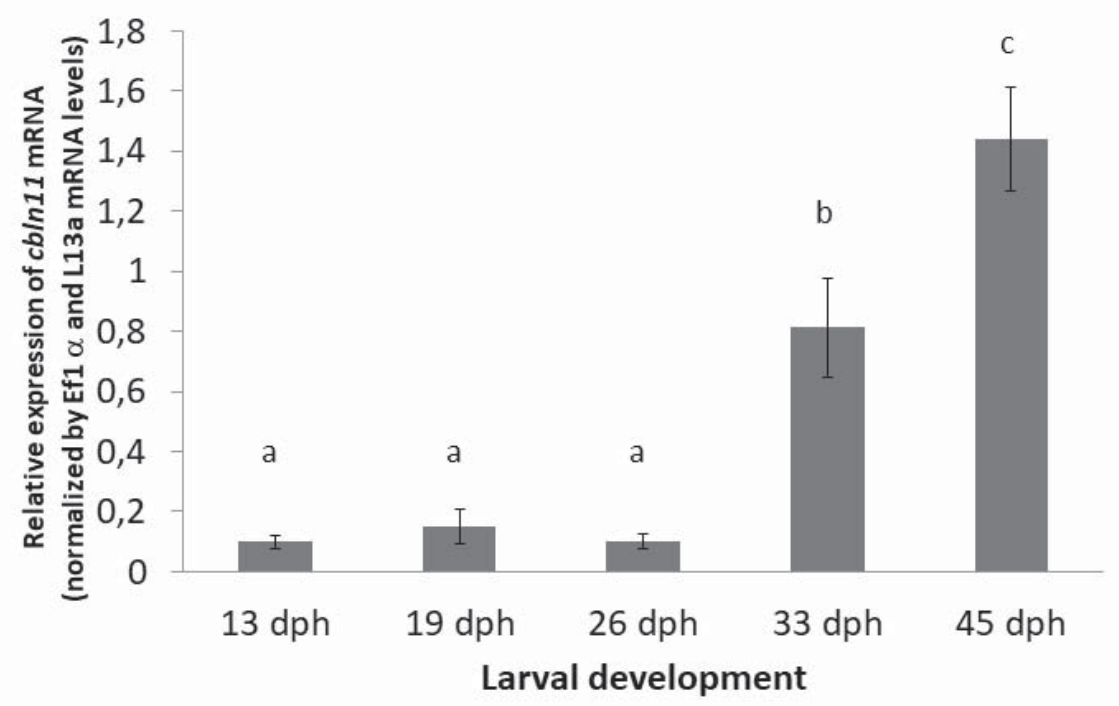




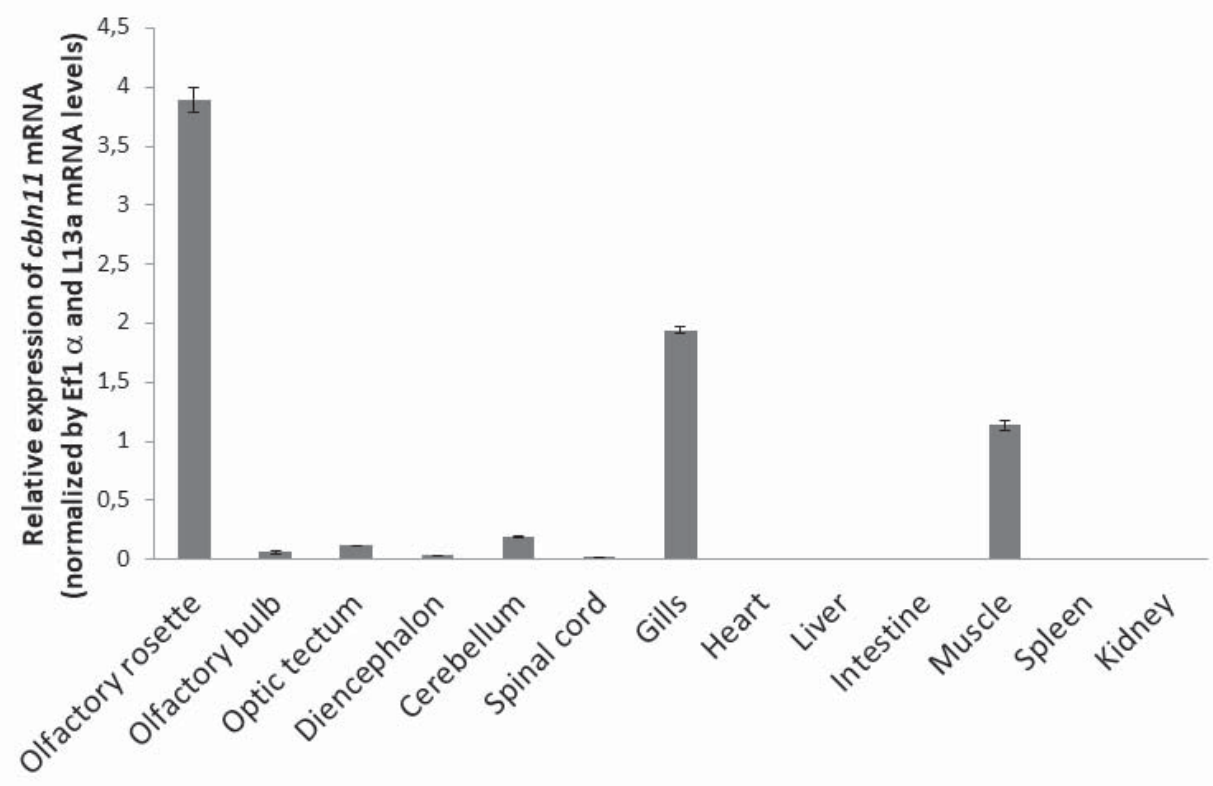



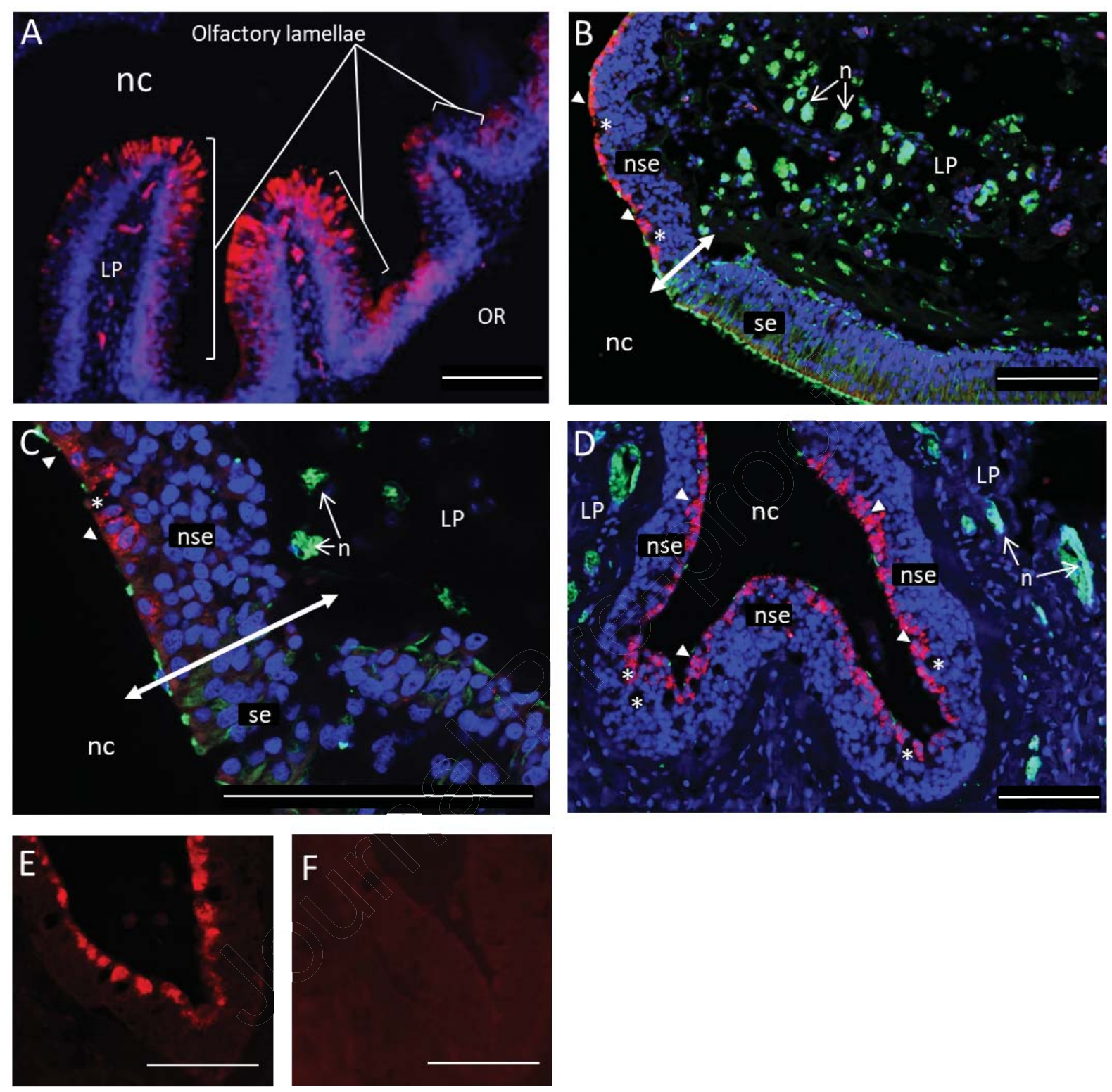

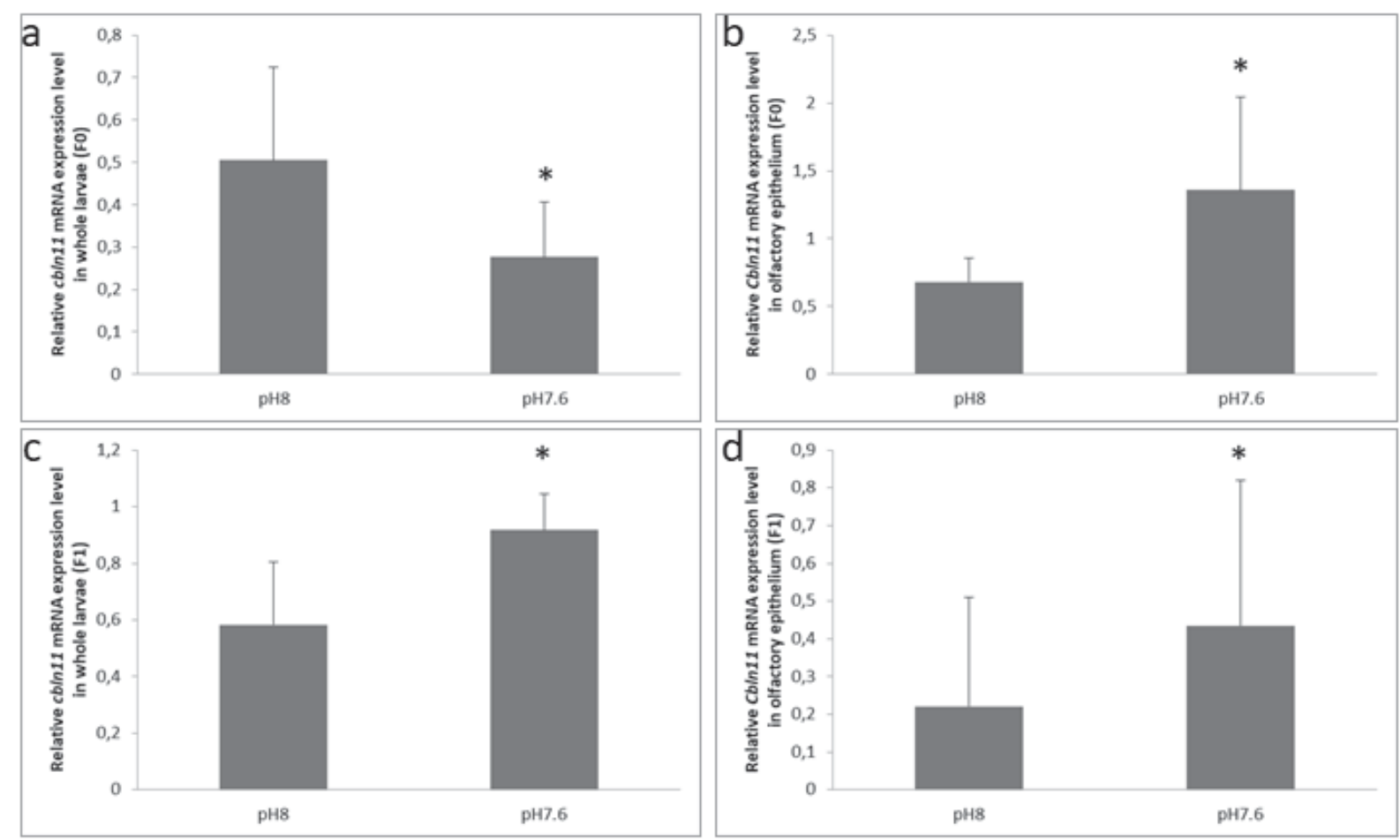


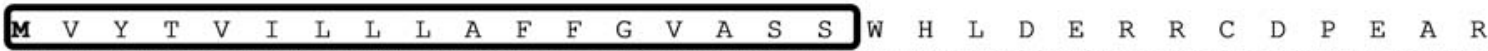
1 atggtctacacggtgattctccttcttgcttttttggagttgcgtcttcctggcacctagatgaacggaggtgcgacccagaggcacga

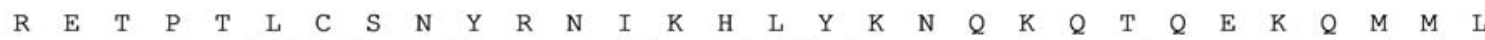
91 agggaaacaccaactctttgctcaaattacagaaacattaaacatctttataaaaaccagaaacagactcaggagaaacaaatgatgctg

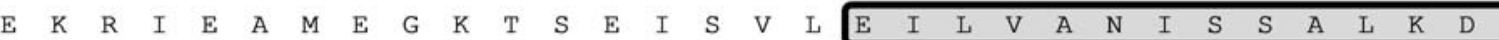
181gaaaaaggattgaggctatggaaggtaagaccagtgaaatcagtgtgcttgaaatcctagtggcaaacatttcgagtgcactaaaggac

\begin{tabular}{lllllllllllllllllllllllllllllllllllll}
\hline L & E & T & M & N & S & Q & N & E & M & E & L & N & D & T & K & A & Q & L & V & K & H & K & A & D & I & A & S & L & K \\
\hline
\end{tabular} ${ }_{271}$ cttgaaacgatgaattcacaaatgagatggaattaaatgacacaaaggcgcagctggtgaaacacaaagctgacatagcgagcctgaag

\begin{tabular}{|llllllllllllllllllllllllllllllllll}
\hline$R$ & $E$ & L & $Q$ & E & L & V & E & H & R & E & I & V & G & G & N & F & S & Q & I & E & D & T & L & F & T & T & E & $R$ & $R$ \\
\hline
\end{tabular} ${ }_{361}$ agagagcttcaagaactggttgaacacagggaaatagttggggggaacttcagtcagattgaagatacacttttacaactgagaggcgg

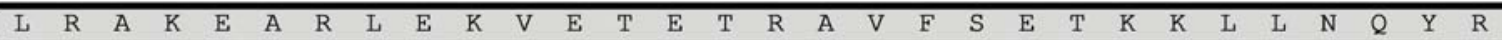
${ }_{451}$ ttgagggcaaaagaagccaggcttgaaaagttgagacagaaaccagggcagtgttcagtgagacaaagaagctcctgaatcaatatagg

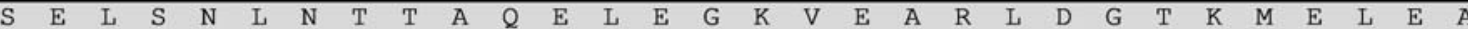
${ }_{541}$ agtgaacttccaacctaacacgacggctcaggagcttgaaggcaaagtcgaagctcgactggatggcacgaagatggaacttgaagct

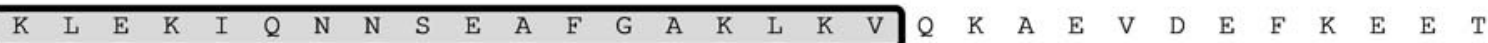
631 aagctggagaaaatacaaaacaacagtgaagctttcggcgcaaaacttaaagtgcaaaaagctgaggttgatgaatttaaggaggaaact

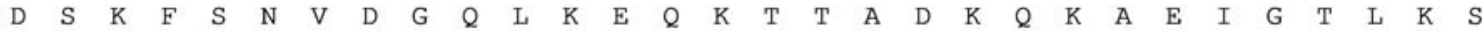
721gacagcaaattcagtaatgttgatggacagctgaaagaacaaaaactacagcggacaagcagaaggctgaaatcggcactctcaagagc

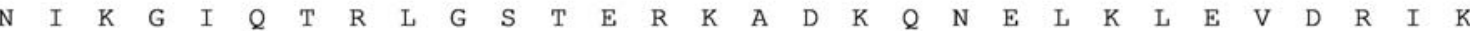
811 aacattaaaggaatacaaaccagactggggtcaactgagagaaaagctgacaaacaaaatgaactcaaactagaggtggacagaattaaa

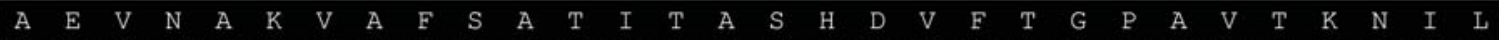
9019cagaagtcaatgcaaaggtggcattctctgcaactataaccgcatctcatgatgtgttcaccggaccagccgtcaccaagaatattctg

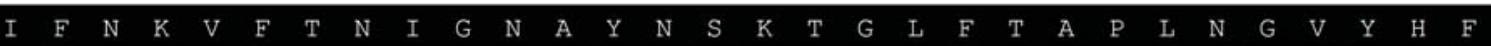
${ }_{991}$ atctttaacaaagtcttcacaaacattggcaacgcttacaactctaaaacaggcctcttcactgctccactgaatggggtttaccacttc

$\begin{array}{llllllllllllllllllllllllllllllllllll}S & F & M & T & S & G & Y & S & C & Y & T & S & G & A & I & \text { L } & V & K & N & G & H & Y & Q & V & S & T & W & E & F & K\end{array}$ 1081 tcattcatgacttctggctacagctgctacacttcaggagccatcctggtgaagaacgggcattaccaagtgagcacctgggagttcaaa

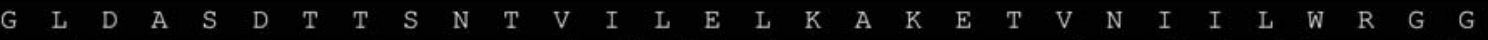
1171ggactggacgccagcgacaccaccagcaacacagtaattcttgaactgaaggccaaagagaccgtgaacatcatactgtggaggggtgga

\section{\begin{tabular}{lllllllllllllll}
$\mathrm{K}$ & $\mathrm{I}$ & $\mathrm{H}$ & $\mathrm{S}$ & $\mathrm{S}$ & $\mathrm{V}$ & $\mathrm{F}$ & $\mathrm{T}$ & $\mathrm{G}$ & $\mathrm{F}$ & $\mathrm{L}$ & $\mathrm{I}$ & $\mathrm{F}$ & $\mathrm{P}$ & $\mathrm{S}$ \\
\hline
\end{tabular}}

1261 aaatacattcaagtgtcttcactgggttcctcatcttcccgtcgtag 


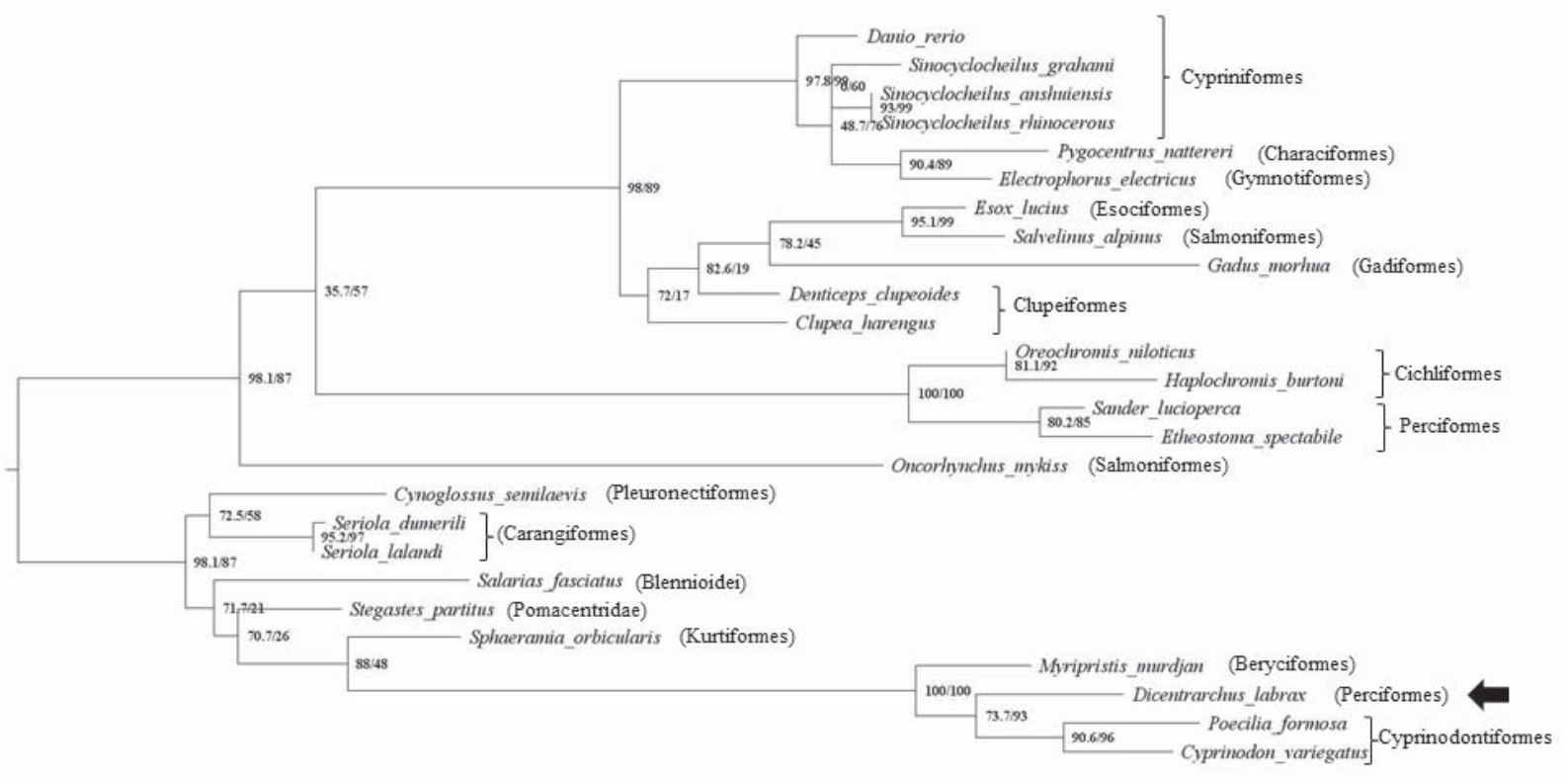


Highlights:

- Cbln11 mRNA is mainly expressed in the olfactory rosettes and in the gills of European sea bass

- Cbln11 mRNA expression is localized in the non-sensory epithelium of the olfactory rosettes

- Long term exposure to ocean acidification induces a stimulation of $c b \ln 11$ mRNA expression in the olfactory rosette of European sea bass

- Ocean acidification-induced stimulation of cbln11 mRNA expression suggests a regulation of innate immune function 


\section{Declaration of interests}

$\bigotimes$ The authors declare that they have no known competing financial interests or personal relationships that could have appeared to influence the work reported in this paper.

$\square$ The authors declare the following financial interests/personal relationships which may be considered as potential competing interests: 